\title{
Facebook: The Power Source of Transforming the Learning Experience
}

\author{
Blessing Mbatha \\ Department of Communication Science, \\ UNISA, Republic of South Africa
}

\begin{abstract}
This article reports on Communication Science students' perceptions of the use of Facebook in their studies as a transformational and educational tool at the UNISA. The problem that was investigated pertains to students' inadequate constructive use of the Learning Management System. A survey research design was used and questionnaires were administered to all Communication Students Association executives (10) and 100 Unisa Radio student employees, chosen by simple random sampling. The data was analysed using thematic categorisation and tabulation and the findings were presented descriptively. The findings indicated that students spend most of their time socialising on Facebook and that students would like see UNISA's academic content posted on Facebook because that is where most students spend most of their time. They based their argument on the premise that on Facebook they meet different people from all over the globe who could assist them in their studies. The students are clearly reaping many benefits from the use of Facebook in their studies and will continue to do so. Therefore, when designing Learning Management Systems for their students, universities should bear in mind that many students prefer to use Facebook for their studies.
\end{abstract}

\section{Introduction}

Social networking sites (SNSs), which are the preferred method of communication of the millennium generation, are also gaining popularity with people from other generations. SNSs have become very popular and are the way the 21 st century communicates today [1]. It is also true that SNSs play a major role in the grouping of individuals into specific groups, like small rural communities or a neighbourhood subdivision, so to speak. Although social networking (SN) is possible in person, especially in the workplace, universities, and high schools, it is most popular online [1].

Facebook is an SNS that started out strictly for college students and was available by invitation only
[2]. Now, it is a cultural phenomenon stretching across the globe. Facebook has taken hold as undisputable leader amongst SNSs. SNSs have become most popular among younger users such as university students [3]. One reason they may have become so popular among younger individuals is that they have an equalising effect in that individuals often feel the freedom to express themselves in ways not possible through other outlets. SNSs have even been found to increase self-esteem among younger people [3]. SNSs such as Facebook, twitter, MySpace, and many others allow vast communities of Internet users to create and maintain profiles of personal information and interact with each other in a variety of ways [4]. The current statistics show that Facebook has more than 500 million active users globally. Fifty per cent of Facebook-active users log in on any given day [5]. SNSs generally give an impression of informal use and entertainment-based escapism. However, they have the potential to influence teaching and learning practice in higher education institutions. It may be possible for higher education institutions to take advantage of students' use of SNSs for the good of an institution by using social networking sites creatively and productively to benefit students' development and to build positive online campus communities [4]. Undergraduate students are beginning to use SNSs to discuss coursework with friends [6]. Facebook is also being used by teachers and students as a communication tool. Since many students are already using a wide range of SNSs, teachers have begun to familiarise themselves with this trend and are now using it to their advantage [7].

This article reports on research on Communication Science students' views on the use of SNSs in their studies as a transformational and educational tool in collapsing the transactional distance by answering the following research question: What are the perceptions of Communication Science students' on the use of Facebook as an educational tool? The problem that was investigated pertains to students' inadequate use of the learning management systems (LMSs), caused by the fact that many students spend most of their time on SNSs chatting amongst themselves. Also of note is that many tertiary institutions world-wide have invested millions in electronic learning (e- 
learning) resources in order to bridge the geographical distance between the students and their institutions. Moreover, e-learning resources can be used to supplement the traditional way of teaching. Yet some students at UNISA do not use these elearning resources adequately [8].

Many studies have been conducted globally on SNS usage in teaching and learning (e.g. [7], [4]. For example, another recent study on the use of electronic learning resources established that the majority of Communication Science students at UNISA do not adequately use e-learning resources for their studies [8]. Rather, they prefer SNSs. UNISA introduced the LMS popularly known as myUnisa as a way of enabling communication between students and students and students and the university. The main intention of introducing myUnisa was to bridge the space of time and geographic location between the students and the university. In a nutshell, myUnisa is an e-learning system that UNISA has put in place for its students. However, students do not make use of this LMS [8]. LMSs seem to be catalysts in teaching and learning, more especially in an open distance learning institution (ODL) like UNISA. If students do not use learning management systems that many tertiary institutions have put in place for them, there would be no effective engagement between the stakeholders in learning. Consequently, throughput might be negatively affected. It is therefore recommended that SNSs be used in conjunction with the LMSs that tertiary institutions have established for their students. Accordingly, tertiary institutions should think of posting students' study material on SNSs because that is where the majority of students spend most of their time.

\section{Literature review}

Facebook plays a major role amongst university students with regard to information sharing and communication. Among online SNs, Facebook stands out for two reasons: its success, both in terms of membership and quality of information available on it; and the fact that, unlike on other networks catering for young users, the information is uniquely and personally identified [9]. Accordingly, Facebook is of interest to researchers in two respects: firstly, the phenomenon itself - with over nine million users - the behavior of its users and the gains as well as the risks they face; and secondly, it is a unique experiment in information revelation, a source of highly valuable information about privacy attitude and privacy behaviour among young individuals. College-oriented SNSs are based "on a shared real space" [9], [10].
Facebook, in particular, has spread to thousands of college campuses across the USA (before targeting high schools) and more than nine million (and counting) users [9]; [10]. In addition, Facebook's market penetration is impressive passing the barrier of 80 percent of the undergraduate population in many colleges. The amount, quality, and value of the information provided are impressive. Also of note is that not only are Facebook profiles most often personally identified, but by default they show contact information (including personal addresses and cell phone numbers) and additional data rarely available on other SNSs. Facebook requires a college's email account for a participant to be admitted to the online $\mathrm{SN}$ of that college. This increases the expectations of validity of certain personal information, as well as the perception of the online space as a closed, trusted and trustworthy community [11], [12]. Unlike other online SNs, Facebook offers its members very granular control on the searchability and visibility of their personal information (in particular, by friend or location, by type of user, and by type of data). Nobody is forced to reveal certain data. However, by default participants' profiles are searchable by anybody else on the Facebook network, and actually readable by any member at the same college. The barriers to entrance to any Facebook college community are low, since various forms of social engineering or technical attacks are possible. Those attacks allow individuals not affiliated to a campus to become members of their Facebook network, or allow information to be visible to members who were not supposed to see it [13], [14]. In addition, the amount and nature of information provided on Facebook have attracted significant concern about Facebook in the media [15]. Facebook has reacted by adapting and extending its privacy policy (without, however, significantly altering its most basic tenets), and by addressing some of its security issues [15], [16], [12].

\section{Theoretical framework}

This article is informed by Satisfaction and Elearner Satisfaction Theory. Satisfaction is an important aspect of product or service marketing because it determines whether a customer will continue using a product or service or not. The theory postulates that when a customer is satisfied with the service(s) offered by an institution or a company, he or she is more likely to continue using that institution's products or services. However, when a client is dissatisfied with the service on offer, he or she may decide to discontinue using that particular product or service. Satisfaction refers to a customer's "cognitive state of being adequately or inadequately rewarded for the sacrifice they have undergone" [17]. In this connection, it should be 
emphasised that the main reason why the students do not adequately use learning management systems (e.g. myUnisa) in their studies could be due to dissatisfaction. One of the main reasons why students do not use LMSs provided by their institutions is the complexity of the systems [8]. According to the students, most of the LMSs are not user-friendly. In addition, the findings of the current study further indicate that most university students prefer to use SNSs like Facebook because there are many people who are on Facebook most of the time. Most of the students in the study referred to above also indicated that the other reason they prefer Facebook over LMS is that on Facebook, for example, they communicate with other students from all over the world and if they happen to experience any challenges regarding their studies, they just put a question on Facebook and it will be answered promptly [8].

\section{Methodology}

A survey research design was used whereby questionnaires were administered to all Communication Science Association (COMSA) executives (10) and 100 Communication Science UNISA Radio student employees who were chosen using purposive sampling to select $50 \%$ of 200 students. These groups were chosen because they were able to provide valuable data emanating from their active involvement at the Muckleneuk and Sunnyside campuses in Pretoria, the hub of the university's activities. In addition, they were chosen because they had physical access to e-learning resources. The response rate was 76 (69\%). The questionnaire sought information pertaining to the demographic profile of the respondents; SNSs used by the students; SNSs used by the students in their studies; factors that motivate the students to use SNSs; frequency in using SNSs; students' views on posting UNISA academic content on SNSs; and major reasons in favour of posting academic content on SNSs. The data collected was analysed using thematic categorisation and tabulation, and the findings were presented descriptively.

In terms of ethical considerations, informed consent was obtained from each participant in the study in order to ensure that they understood what they were doing and verified their willingness to participate. The respondents were assured of their rights, including the right of consent, protection from disclosure of information, and respect for their privacy. All the research participants voluntarily participated and were not forced to take part in the study. With regard to protection from harm, the researchers ensured that the participants were not at any risk and would not be exposed to embarrassment, unusual stress or any demeaning treatment. Anonymity and confidentiality were promised and maintained. The information they provided was not made available to anyone else who was not directly involved in the study and could not be traced back to the participants. In terms of professional standards, the researchers ensured that the results were gathered in a professional manner without misrepresenting anyone and/or intentionally misleading the respondents about the nature of the study. The researchers ensured that all the findings were presented honestly without fabricating any data to support any particular finding. The researchers also adhered to the institutional guidelines on conducting research.

\section{Results}

The results are reported in the following categories: demographic profile of the respondents; SNSs used by the students; SNSs used by the students in their studies; factors that motivate the students to use SNSs; frequency in using SNSs; students' views on posting of UNISA's academic content on SNSs; and major reasons for posting UNISA's academic content on SNSs.

\subsection{Demographic profile}

The study was male dominant (67\%) while females constituted only $33 \%$. Most of the respondents were between the ages of 20 and 29 years $(89 \%)$, while only $(11 \%)$ were between 30 and 39 years. With regard to marital status, all the respondents were single and were residing in urban areas. In as far as the level of study was concerned, the majority of the respondents $(57 \%)$ were in their third level of study.

\subsection{SNSs used by the students for recreational purposes}

One of the objectives of the study was to establish the types of SNSs the students use for recreational purposes. SNSs have been adopted in teaching and learning in order to supplement the traditional methods of teaching and learning [8]. A list of SNSs was provided to the students to choose from as was applicable to their situation and they were asked to choose more than one option where necessary. Figure 1 summarises the responses. 
SNSs used by the students for recreational purposes
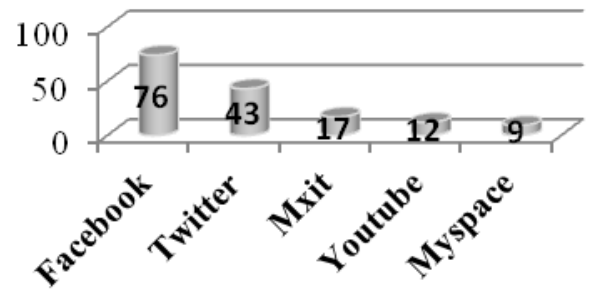

Figure 1: SNSs used by the students for recreational purposes $(\mathrm{N}=76)$

NB The figure above includes multiple responses

Figure 1 shows that all the students $76(100 \%)$ use Facebook for recreational purposes, while 43(57\%) used twitter. When it comes to those who use mxit, only $17(22 \%)$ reported to use it and only $12(16 \%)$ use YouTube. The findings further indicate that only $9(12 \%)$ of the students use Myspace for recreational purposes. These findings confirm what some ICT enthusiasts pointed out that Facebook is the leading SNS that is used by many students in tertiary institutions for both educational and recreational purposes [4].

\subsection{SNSs used by the students for educational purposes}

After the students were asked to indicate the SNSs they use, it was important for them also to indicate the SNSs they use for educational purposes. Once again, the respondents were provided with a list of SNSs to choose from and asked to respond as was applicable to their situations (illustrated in Figure 2). The students were allowed to choose more than one option where necessary.

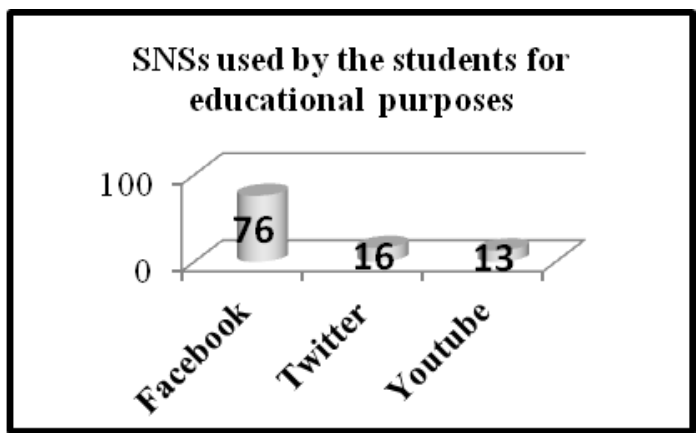

Figure 2: SNSs used by the students in their studies $(\mathrm{N}=76)$

NB The figure above represents multiple responses
The figure above shows that all the students $76(100 \%)$ used Facebook for educational purposes, while 16(21\%) used twitter and only 13(17\%) used YouTube for educational purposes. This could be attributed to the fact that there is a lot of information which students can access on Facebook.

\subsection{Students' reasons for using Facebook for educational purposes}

The respondents were required to reflect on the main reasons for their preference to use Facebook in their studies over other SNSs. When asked to provide reasons for using Facebook in their studies, the students noted the following (quoted verbatim; the abbreviation FB used for Facebook):

- "My friends are always on FB. As a result, we do not use discussion forums on myUnisa”

- "I can always communicate with my fellow classmates”

- "Sometimes I do not receive updates from the UNISA fan page”

- $\quad$ "FB helps me a lot when I do research for my studies"

- "I use FB to communicate with my fellow students especially those that I do not get to see on campus due to geographical location"

- "Studying through FB helps me engage with both national and international students"

- $\quad$ "There is a lot of information that one can find on FB which is not on myUnisa"

- "FB enables me to interact with my fellow students and lecturers about challenges we face in our studies"

These findings concur with the study conducted by an ICT enthusiast who established that online SNs offer exciting new opportunities for interaction and communication [7]. Among them, Facebook stands out for its vast membership, its unique and personally identifiable data, and the window it offers on the information-relevant behaviour of young adults.

\subsection{Students' views on posting UNISA's academic content on Facebook}

Students' views were required as to whether it was necessary for UNISA to post its academic content on Facebook because that is where many 
UNISA students spend most of their time compared to the time they spend on myUnisa. In order to measure their responses, a binary choice of $1=$ Yes and $2=$ No was used. The study established that the majority of the respondents $73(96 \%)$ would like to see UNISA's academic content posted on Facebook, while only $3(4 \%)$ said they did not want to see UNISA's academic content on Facebook. This shows that there is more reliance on Facebook among the students.

\subsection{Students' reasons for posting UNISA's academic content on Facebook}

The students were required to provide their motivation for posting UNISA academic content on Facebook. The findings show that the main reasons why students prefer to see UNISA's academic content on Facebook are expressed in the following verbatim and unedited responses:

- "A number of UNISA students participate in discussion forums on Facebook. Thus, FB helps the students to share and disseminate knowledge related to their studies"

- "If UNISA's academic content is posted on FB, it would increase my chances of meeting both my national and international fellow students and lecturers pertaining to the challenges of being a student in the 21 century and in an ODL institution"

- $\quad$ "FB is more interactive and a useful SNS. I use it to interact with a lot of people nationally and internationally"

- "Posting UNISA's academic content on FB would allow frequent access to information because majority of students can be easily accessible on $F B$ ",

- "I would get frequent update on my studies because I am on FB every day"

- "It would be great in view of the fact that my fellow classmates are always on FB instead of discussion forums on myUnisa",

- "FB is user friendly. It also gives one time to interact with it and gives feedback"

\section{Discussions}

It is clear that Facebook has a great impact on the lives of university students. Their use of Facebook not only assists them on campus, but may also partially define the university experience of this generation. Facebook is a place where students find sources for their studies, interact with their lecturers outside classes, communicate among themselves and share knowledge with other people all over the world. A similar study established that in their free time, many students use Facebook to express themselves creatively, share their beliefs, engage in dialogue with others, and define (and redefine) themselves [18]. There is clear evidence that students use Facebook regularly, but for the most part, these activities are not integrated into all aspects of their university experience [18]. It should be noted that not all students are comfortable with participating in real-time, real-life student groups on campus, nor do all students have the ability to be in the same place at the same time. These students may be more comfortable with the anonymity and community provided by an online student group through a social networking site [19].

While Facebook and other uses of online communities have many advantages, it is important to note the limitations inherent in using these tools for outreach to students. Even though these tools may facilitate communication among students who would not otherwise meet in person, there are drawbacks to online methods. One significant disadvantage is the so-called digital divide between students who have readily available access to the Internet and computers and peripherals needed to navigate it efficiently, as well as to students who do not have these resources [20]. Access may be an issue for first-generation and low-income students and those from rural areas where low-speed Internet connections keep them from using websites to the fullest extent. Furthermore, if a student does not own a computer, sharing a roommate's computer or visiting on-campus computer laboratories may not only be less convenient, but also less private and therefore less safe for exploring issues of identity. Student support programmes could integrate technology and provide access to computers as one solution to the digital divide and access concerns.

Another issue that is important to address with the use of SNSs is the potential for addiction and distance between students. For those just entering the university environment, the lure to spend more time chatting than studying is great [21]. An earlier study established that a new student is faced with newfound freedom, less parental involvement and control, and large blocks of unstructured time [22]. These factors, combined with alienation or awkward social skills, may direct many new students to turn to the Internet instead of developing social circles on campus [22]. A final concern to note here is the potential for the invasion of privacy and personal safety concerns. As students use SNSs to create profiles, there are no pre-imposed limits to the amount of private information they can post about themselves. The inaccurate belief that only a limited 
community of close friends is interested in or looking at a student's profile can lead to issues of cyber-stalking, code of conduct violations, or other negative results [23]. Students who are new to using these sites may not be aware of the privacy controls or security issues. Student affairs administrators can help educate students to consider their online privacy as well as their personal safety [23].

Another important point to observe is that the majority of the students would prefer to use Facebook over myUnisa because Facebook is user friendly. Some of the students further indicated that they prefer to use Facebook to other LMSs because it gives them time to interact with it and it gives feedback. These findings confirm what the Satisfaction and E-learner Satisfaction Theory postulates. As indicated earlier, this theory postulates that when a customer is satisfied with the service(s) offered by an institution or a company, he or she is more likely to continue using that institution's products or services. However, when a client is dissatisfied with the service on offer, he or she may decide to discontinue using that particular product or service [17]. It is worth mentioning that innovations are more readily adopted when they provide a relative advantage compared to old ideas [24]. It is clear from the results of this study that Facebook provides a new and innovative way of teaching and learning. Innovation theorists postulate that there are certain characteristics that determine the rate at which an innovation is adopted by a social system. These characteristics include relative advantage, compatibility, complexity, trial-ability and observability of the innovation. Thus the majority of students prefer to use Facebook instead of other LMSs because Facebook provides a relative advantage to the students. Also, students find that Facebook is not difficult to use, as the majority indicated that it is user friendly. SNSs have become most popular among younger users such as university students [3]. One reason they may have become so popular among younger individuals is that they have an equalising effect in that individuals often feel the freedom to express themselves in ways not possible through other outlets. SNSs have even been seen to increase self-esteem among younger people [3]. It is argued that one will not only make new friends, but one might learn a thing or two about new cultures or new languages and learning is always a good thing [13]. Also of note is that students can learn from their online friends how to solve a particular problem they are experiencing in their studies.

\section{Conclusion}

The main aim of this article was to report on Communication Science students' views on the use of SNSs in their studies as a transformational and educational tool in collapsing the transactional distance at UNISA. In answering the research question, the results of this study indicate that students concur that Facebook plays a major role in their studies. Also of note is that all the students revealed that they use Facebook in their studies because it enables them to interact with their national and international fellow students. It is clear that the students are reaping many benefits by using Facebook and will continue reaping more benefits in their studies. Therefore, when designing LMSs for their students universities should bear in mind that the majority of students prefer to use SNSs for their studies. It is worth mentioning that if tertiary institutions post their academic contents (i.e. messages and announcements) on SNSs students would engage more effectively with their study material because that is what they prefer. This might improve throughput, which all institutions are striving for. This can be done by posting academic content on an SNS. The content could range from study material, feedback on assignments, examination preparation, previous question papers, assignments and student results, to name but a few aspects. It is clear that SNSs are revolutionising the way teaching and learning is done and are continuing to be key catalysts in the academic setting.

\section{Recommendations for further study}

This article serves as a foundation for further study on UNISA's student perceptions on the use of Facebook in their studies as an educational tool for bridging the transactional distance. This article demonstrates that much more research is needed on the perceptions of UNISA students on the use of SNSs. This research relied only on the views of Communication Science students at UNISA, thus a broader study that will sample all UNISA students is recommended. Based on the number of participants on the study, these results could not be generalised. Also, in the light of the results, it is recommended that an in-depth study be conducted to ascertain core issues in respect of why students do not engage actively with what is meant to promote a deep learning experience (LMSs). Furthermore, this study relied on group samples of UNISA students in urban locations (Pretoria campuses) and was thus not representative of all the living areas (rural and urban). Therefore, future studies that include representative samples of students from rural and urban areas could contribute further to the understanding of SNSs usage at UNISA [13]. It is also suggested that future study should focus on the lecturers' perceptions on the use of SNSs in teaching and learning. 


\section{References}

[1] Brown, K. (2010) What Is Social Networking? http://www.whatissocialnetworking.com/ (20 June 2011).

[2] Top Ten Reviews (2010) Social Networking Websites Review; http://social-networkingwebsites-review.toptenreviews.com/ (15 June 2012).

[3] Kim, K.-H., and Yun, H. (2007) Cying for me, Cying for us: Relational dialectics in a Korean social network site. Journal of Computer-Mediated Communication, (1), pp. 15.

[4] Aleman, A.M and Wartman, K. L. (2009) Online Social Networking on Campus: Understanding What Matters in Student Culture. Routledge: New York.

[5] Facebook (2012) Statistics: People on Facebook; http://www.Facebook .com/press/info.php?statistics (12 August 2012).

[6] Bassford, M and Ivins, J. (2010) Encouraging formative preview via Social Networking Sites. British Journal of Educational Technology, (5), pp. 67-69.

[7] Liebeskind, J.P. (1996) "Social Networks, Learning, and Flexibility: Sourcing Scientific Knowledge in New Biotechnology Firms". Organization Science, (4), pp. 428-443.

[8] Mbatha, B.T. and Naidoo, L. (2010) Challenges hampering the collapse of distance in Open Distance Learning, Progressio, (1), pp. 170-184.

[9] Lyon, D. (2006). Theorizing surveillance: The panopticon and beyond. Willan Publishing: Cullompton, Devon.

[10] McGrath, J.E. (2004) Loving big brother: Performance, privacy and surveillance space. Routledge: London.

[11] Malcolm R. P. and Floyd, K. (1996). "Making friends in cyberspace," Journal of ComputerMediated Communication, (4), pp. 24-39.

[12] Gross, R. and Acquisti, A. (2005) Privacy and information revelation in online social networks. In proceedings of the ACM CCS Workshop on Privacy in the Electronic Society (WPES '05). Alexandria, VA, USA — November 07 - 10, 2005. pp. 71-80.

[13] Nip, J. (2004) "The relationship between online and offline communities: The case of the queer sisters," Media, Culture \& Society, (3), pp. 409428.

[14] Poster, M. (1996) "Databases as discourse; or, Electronic interpellations," In David Lyon and Elia Zureik (editors). Computers, surveillance, and privacy. Minneapolis: University of Minnesota Press, pp. 175-192.

[15] Taylor, T.L. (2006) "Does WoW change everything? How a PvP server, multinational player base, and surveillance mod scene caused me pause," Games \& Culture, (4), pp. 318-337.

[16] Orwell, G. (1949) Nineteen eighty-four, a novel. Secker \& Warburg: London.

[17] Kim, M. K., Yeon, G. D. and Park, M-C. (2002). Determination of Customer Retention for the Korean High-Speed Internet Service. Seoul: In proceedings of the $14^{\text {th }}$ Biennial International
Telecommunications Society Conference, Montreal. June 24-27.

[18] Gasser, H.S. (2008) Being Multiracial in a Wired Society: Using the Internet to Define Identity and Community on Campus. Wiley Periodicals, Inc. No. 123. pp. 63-71.

[19] Burleson, D. A. (2005) "Logging On: How Technology Has Impacted the Identity Development of Gay Males". Student Affairs Online, (4), pp. 33-42.

[20] Galuszka, P. (2007) "Digging Out of the Digital Divide." Diverse Issues in Higher Education, (2), pp. 21.

[21] Jones, S. (2002) The Internet Goes to College; http://www.pewInternet.org/pds/PIP_College_Rep ort.pdf (23 August 2010)

[22] Young, K. (2001) "Surfing Not Studying: Dealing with Internet Addiction on Campus". Student Affairs Online, (2), pp. 43-51.

[23] Wilson, S. (2007) "The Influence of Technology on College Student Values". Student Affairs Online, 2007, (3), pp. 31-45.

[24] Rogers, E. M. (1995) Diffusion of Innovations, Free Press: New York. 